\title{
I solation, characterization and antibiotic susceptibility profile of Staphylococcus aureus from raw milk samples in Nagpur district, India
}

\author{
Preeti G . Dharmik* and A shok V. Gomashe \\ Shri Shivaji Science College, Congress nagar, Nagpur- 440012 (M.S.), INDIA \\ *Corresponding author. E-mail: preeti.dharmik5@gmail.com
}

\begin{abstract}
The study was carried out from July 2010 to June 2011. The aim of the present investigation was to isolate Staphylococcus aureus from raw milk obtained from cow from different parts of Nagpur district, India and to determine their antibiotic susceptibility profile. General biochemical tests along with the MASTASTAPH ${ }^{\mathrm{TM}}$ rapid agglutination tests were employed for bacterial identification. All the well characterized isolates were further confirmed by amplifying coa gene by PCR. A total $95 \mathrm{~S}$. aureus isolates were obtained during this study from 50 raw milk samples. When all the well characterized isolates were subjected to antibiotic susceptibility testing, erythromycin and chloramphenicol were the most effective antibiotics. A large proportion of isolates were found to be resistant to Co-trimoxazole (89\%) followed by Linomycin (81\%) and Penicillin (35\%) It was concluded from the current study that the hygiene of the milk was poor and resistant strains contaminated the milk probably during the process of transportation.
\end{abstract}

Keywords: Antibiotic susceptibility, Staphylococcus aureus, Raw milk

\section{INTRODUCTION}

Milk is a very nutritional food that is rich in carbohydrates, proteins, fats, vitamins and minerals. However, health risk to consumers can be associated with milk due to the presence of zoonotic pathogens and antimicrobial drug residues (Astal et al., 2002). The quality of milk may be lowered by a number of factors such as adulteration, contamination during and after milking and the presence of udder infection (Bauer et al., 1966). Pathogenic organisms in milk can be derived from the cow itself, the human hand or the environment (Astal et al., 2002).

Staphylococci are normal Inhabitants of the skin and mucous membranes of animals and humans. Pathogenic strains are usually coagulase- positive (Braddy, 2002), and have been found to cause diseases in their hosts throughout the world (Chigbu and Ezeronye, 2003; Collins et al., 2010). Diseases in cattle caused by Staphylococcus aureus range from simple abscesses and mastitis to the severe toxic shock syndrome (Devriese et al., 1997; Chigbu and Ezeronye, 2003; Collins et al., 2010).

Staphylococcal mastitis is the commonest and economically the greatest concern wherever dairy farming is practiced. The chief reservoir of this bacterium is an infected udder. A bacterium is shed into milk from infected quarters (Esron et al., 2005). The prevalence of mastitis and its associated pathogens in animals can be reduced by improved on the farm management techniques within the dairy industry (Evenson et al., 1988). It is thus paramount importance to ensure that proper hygiene practices are enforced in both the areas where the animals are kept and the milking environment.

Although it is difficult to control mastitis caused by S. aureus with antibiotics only (Farzana et al., 2004), various antimicrobial agents are constantly being used to treat this disease in cattle (Garrod et al., 1981). This practice results in the development of antibiotic resistant strains. The usage of antibiotics correlates with the emergence and maintenance of antibiotic resistant traits within pathogenic strains (Hassan et al., 1978). These traits are coded by particular genes that may be carried on the bacterial chromosome, plasmids, transposones or on gene cassettes that are incorporated into integrons (Larsen et al., 2000) thus are easily transferred among isolates.

Determination of levels of $S$. aureus and an evaluation of the antibiotic-resistant phenotypes of the isolates could serve as a tool for determining the hygiene standard implemented during milking. Data on antibiotic resistance could also be used to characterize these opportunistic pathogens, which may further limit the risks associated with the consumption of contaminated milk and its products (Mahon and Larsen, 1995).

The resistance of $\mathrm{S}$. aureus isolates from different parts of the world to commonly used antibiotics has been widely reported (Odongo and Ambani, 1989; Matsunaga et al., 1993; NCCLS, 1999; Malahat et al., 2010). The study aimed at isolation and characterization of $\mathrm{S}$. aureus by traditional and molecular biology techniques and determining the sensitivity pattern of different isolates of $\mathrm{S}$. aureus from milk samples in Nagpur district, India 
to commonly prescribed antibiotics.

\section{MATERIALS AND METHODS}

Place of work: The study was conducted at Department of Microbiology, Shivaji Science College, Nagpur India. Fifty milk samples were collected from different areas in Nagpur district during July 2010 to June 2011 and 95 strains were isolated from these milk samples.

Collection of samples: Fifty samples of raw milk $(250 \mathrm{ml})$ were collected ascetically in sterile glass bottles from milk venders. All the milk samples were immediately transported and tested within three hours of their collection.

I solation of presumptiveS. aureus from milk samples: Two-fold serial dilutions were performed using $2 \%$ peptone water and aliquots of $100 \mu 1$ from each dilution were spread plated onto Manitol salt agar (MSA) Himedia- Mumbai. The plates were incubated aerobically at $37^{\circ} \mathrm{C}$ for $18 \mathrm{hrs}-24 \mathrm{hrs}$. Consequently the 20 characteristic $\mathrm{S}$. aureus colonies those were yellow in color from each MSA plate were further purified by sub culturing onto MSA plates and the plates were retained for further bacterial identification.

Bacterial identification: Gram staining was performed and Gram positive cocci that occurred in clusters under the microscope were subjected to preliminary biochemical tests (catalase and oxidase tests). The identities of the isolates were confirmed based on positive results for the DNase test, beta hemolytic patterns on blood agar enriched with $5 \%(\mathrm{v} / \mathrm{v})$ blood and the rapid latex agglutination slide test for $\mathrm{S}$. aureus using the MASTASTAPH $^{\mathrm{TM}}$ (Onasanya et al., 2003). The slide agglutination test was performed according to the manufacturer's instructions.

In addition to the above characterization all the previously characterized S. aureus isolates were further confirmed by amplifying coa gene (Pitkala et al., 2004).

Antibiotic susceptibility testing: Antibiotic susceptibility test was performed on all the S. aureus isolates to determine their antibiotic resistance profile. Overnight cultures were prepared and used for antibiotic sensitivity tests. An aliquot (100iL) from each isolate suspension was spread plated on Muller Hinton agar (MHA) (Himedia, India). Susceptibilities of the isolates to a panel of 13 different antibiotic discs were determined. The antibiotics tested are shown in fig. 1 and are selected because large numbers of bacteria resistant to these had been documented in the study area. Antibiotic discs were gently pressed onto the inoculated Muller Hinton agar to ensure intimate contact with the surface and the plates were incubated overnight (Sears, 2003). Inhibition zone diameters were measured and values obtained from the National Committee on Clinical Laboratory Standards were used to interpret the results obtained. $\mathrm{S}$ aureus isolates were classified as resistant, moderately sensitive or susceptible to a particular antibiotic.

\section{RESULTS}

In a total of 50 raw milk samples, S. aureus was biochemically, serologically and genetically identified in 95 isolates. These 95 isolates were subjected to thirteen commonly prescribed antibiotics (Fig.1).

According to the results of antibiotic sensitivity of $\mathrm{S}$. aureus, $100 \%$ susceptibility was observed against erythromycin and chloramphenicol. Gentamycin was found to be sensitive against $96 \% \mathrm{~S}$. aureus isolates. The susceptibility of the other antibiotics in decreasing order against $\mathrm{S}$. aureus was found to be Kanamycin (92\%), Streptomycin (91\%), Methicillin (89\%), Ampiclox $(86 \%)$ and Augmentin (81\%). A large proportion of isolates were found to be resistant to Co-trimoxazole (89\%) followed by linomycin (81\%), Penicillin (35\%) and Ampicillin(32\%).

\section{DISCUSSION}

In the current study, we described the isolation and antibiotic susceptibility characterization of $\mathrm{S}$. aureus from raw milk obtained from different areas of Nagpur district, India. The present study pointed out that the milk drawn from healthy animals may be free of bacteria but it becomes contaminated by hands of milkman or from the udders of animals harboring microorganisms. Dirty teats with dung and mud are the dirt source of bacteria from milk. Moreover the utensils used for the milk are also the source of various types of bacteria but the main source is the contaminated water that is added to milk to increase its quantity. All these results showed that raw milk passes through very unhygienic condition during transportation. Moreover, it takes long time to reach the consumer and during that time it becomes highly contaminated because of high temperature which causes the proliferation of bacteria. Hassan et al. (1978) studied tetracycline and erythromycin as effective antibiotics against $\mathrm{S}$. aureus. Shoemaker and Yow (1954) and Uwaezuoke and Aririatu (2004) also reported similar findings against $\mathrm{S}$. aureus isolates when large doses of erythromycin were given intravenously. The results of the present study are similar to those of above workers. In addition to this in given study Chloramphenicol was also found to be effective against all the isolates of $\mathrm{S}$. aureus. According to Garrod et al. (1981), Penicillin is still effective antibiotic against $S$. aureus. In the study $65 \%$ isolates of $S$. aureus were sensitive to penicillin and more than $30 \%$ were resistant, this may be due to extensive use of penicillin that has developed resistance. Devriese et al. (1997) isolated S. aureus strains from bovine mastitis and reported that âlactamase labile penicillin's had 51\% isolates resistant in 1996 , tetracycline resistant strains were $21 \%$ in 1971 and 9\% were found during 1996 and 10\% resistant isolates 


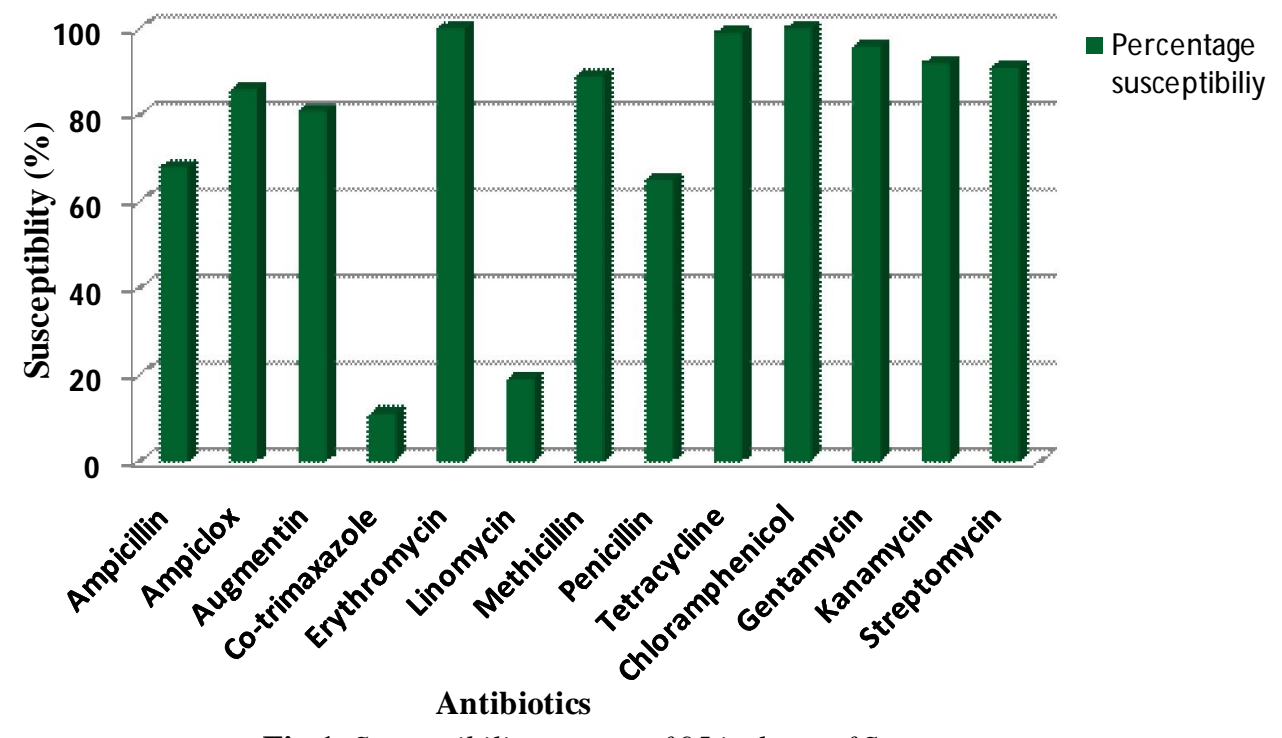

Fig.1. Susceptibility pattern of 95 isolates of $S$. aur eus.

with linomycin in 1996. The results of the present study were similar to the work carried out by Devriese et al. (1997).

In the present work more than $86 \%$ isolates were sensitive and $12 \%$ isolates were resistant to ampiclox. Augmentin showed $81 \%$ sensitivity against $\mathrm{S}$. aureus. In case of Cotrimaxazole $89 \%$ isolates of $\mathrm{S}$. aureus were found resistant to these antibiotics, this may be due to the excessive and long term use of antibiotics.

The present study demonstrated that the resistant strains may have been transferred to cow and then to milk, which can be the reason of infection in human beings if we take raw milk. This can be prevented by improving hygienic condition and careful handling of cow during milking.

\section{REFERENCES}

Astal, Z., EI-manama, A. and Sharif, F.A. (2002). Antibiotic resistance of bacteria associated with community acquired urinary tract infection in the southern area of Gaza Strip. J Chemother, 14 (3):259-64.

Bauer, A.W., Kirby, W.M.M., Sherris, J.C. and Truck, M. (1966). Antibiotic Susceptibility testing by standardized single disc method. Am. J. Clin. Pathol., 45: 493-496.

Braddy, A.J. (2002). B ovine mastitis an evolving disease. Vet J . $164: 116-128$.

Chigbu, C.O. and Ezeronye, O.U. (2003). Antibiotic Staphylococcus in Abia State, Nigeria. African J Biotech, 2 (10) : 374-378.

Collins, N., Ateba, Moses Mbewe, Modisane, S., Moneoang, Cornelius, C. and Bezuidenhout (2010). Antibiotic resistant S. aureus isolated from milk in the Mafikeng area, North West province, South Africa. S. Afr. J. Sci., $106: 11$ - 12.

Devriese, L.A., Haesebrouck, F., Hommez, H. and Vandermeersch, R. (1997). A 25-year survey of antibiotic susceptibility testing in Staphylococcus aureus from bovine mastitis in Belgium, with special reference to penicillinase. Vlaams Diergeneeskundig Tijdschrift, 66 : 170-173.

Esron, D., Karimuebo, E., Lughano, T., Kusilika, R. H.,
Melegela, Aglowisye, M., Kappa, M. and Kalvin, S. (2005) Study on mastitis, milk quality and health risk associated with consumption of milk from pastoral herds in Dodoma and Morgora region, Tanzania. Vet. Sci., $6: 213$ - 221.

Evenson, M.L., Hinds, M.W., Bernstein, R.S. and Bergdoll, M.S. (1988). Estimation of human dose of staphylococcal enterotoxin A from large outbreak of staphylococcal food poisoning involving chocolate milk. Int J F ood M icrobiol 7:311-316

Farzana, K., Nisar, S., Shah, H. and Jabee, F. (2004). Antibiotic resistance pattern against various isolates of Staphylococcus aureus from raw milk samples. J Research Science, 15 (2) : 145 - 151.

Garrod, L.P., Lambert, H.P. and Grady, F.O. (1981). In: Antibiotic C hemotherapy, 5th ed., Churchill, Livingstone, Edinburgh.

Hassan, Z.A., Shaw, E.J. and Shooter, R.A. (1978). Changes in antibiotic sensitivity in strains of Staphylococcus aur eus. Brit. Med. J., 2: 536 .

Larsen, H.D., Sloth, K.H. and Elsberg, C. (2000). The dynamics of Staphylococcus aureus intramammary infections in nine Danish dairy herds. Vet M icrobio., 71 : 89-101.

Mahon, C.R and Larsen, H.S. (1995). Staphylococcus aureus. In: Mahon CR, Manuseseilis G Jr., editors. Textbook of diagnostic microbiology. New York: WB Saunders Company, pp. 325-330.

Malahat Ahmadi, Sayad Mehdi Razavi Rohani, Nooshin Ayremloun (2010). Detection of Staphylococcus aureus in milk by PCR.C omp Clin Pathol, 19: 91-94.

Matsunaga, T., Kamata, S., Kakiichi, N. and Uchida K. (1993). Characteristics of Staphylococcus aureus isolates from peracute, acute and chronic bovine mastitis. J Vet M ed Sci., $55: 297-300$

NCCLS, National Committee for Clinical Laboratory Standards (1999). Performance standards for antimicrobial disk and dilution susceptibility tests for bacteria isolated from animals. Approved standard M13-A. Wayne: NCCL.

Odongo, O. and Ambani, A. (1989). Microorganisms isolated from bovine milk samples submitted to veterinary diagnostic laboratory, Kabete, Kenya. Bull Anim H ealth Prod Afr., 37: 
195-196.

Onasanya, A., Mignouna, H.D. and Thottappilly, G. (2003). Genetic fingerprinting and phylogenetic diversity of Staphylococcus aureus isolates from Nigeria. African J. Biotech, 2(8):246-250.

Pitkala, A., Haveri, M., Pyorala, S., Myllys, V. and HonkanenBuzalski, T. (2004). B ovine mastitis in Finlaand- Prevalence, distribution of bacteria and antimicrobial resisatnce. J D airy Sci., 87: 2433-2441.
Sears, P.M. and McCarthy, K.K. (2003). Management and treatment of Staphylococcal mastitis. Vet Ciin N orth Am F ood Anim Pract., 19:171-185.

Shoemaker, E.H. and Yow, E.M. (1954).Clinical evaluation of erythromycin. Arch. Intern. M ed., 3: 397-401.

Uwaezuoke, J.C., Aririatu, LE. (2004). A servey of Antibiotic resistant Staphylococcus aureus strains from clinical sources in Owerri.J Appl Sci Environ Managt., 8(1):67-8. 